\title{
Insulin Pump Use in Type 2 Diabetes
}

\author{
Bruce W. Bode, M.D., F.A.C.E.
}

\begin{abstract}
Continuous subcutaneous insulin infusion (CSII) for type 2 diabetes mellitus (T2DM) is a promising therapy, but the clinical evidence supporting it is mixed. Large randomized controlled trials have concluded that CSII was equivalent to multiple daily injections (MDI), whereas smaller trials have concluded that CSII was superior. Simpler insulin regimens of CSII have been investigated for T2DM and may lead to improved outcomes. Future directions in this area include simpler insulin pumps and the use of concentrated insulins (U-500), neither of which has left the feasibility stage of research. CSII may be appropriate for some people with T2DM, especially those for whom MDI therapy has failed.
\end{abstract}

\section{Introduction}

$\mathbf{P}$ EOPLE With TYPe 2 diabetes mellitus (T2DM) often require insulin therapy, especially as beta-cell function declines with the progression of the disease. The current American Diabetes Association (ADA)/European Society for the Study of Diabetes consensus treatment algorithm ${ }^{1}$ for T2DM includes basal insulin therapy at Step 2 (Tier 1) and intensive insulin at Step 3 (Tiers 1 and 2). Given the increasing amounts of insulin required by people with T2DM and the failure of any single insulin regimen to obtain glycemic control over the long term, ${ }^{2}$ continuous subcutaneous insulin infusion (CSII) or insulin pump therapy has been explored as an alternative to conventional or intensive insulin therapy using one or more daily injections. In addition, over one-third of people with T2DM on multiple daily injections (MDI) still do not achieve the ADA hemoglobin A1c (HbA1c) goal of $<7 \%{ }^{2}$ The advantage of CSII is the ability to infuse precise amounts of insulin at a continuous basal rate to control glucose when not eating and prandial and correction boluses to cover food intake and out of range glucose values, respectively. When used appropriately, CSII can closely mimic the insulin provided by a normally functioning pancreas. ${ }^{3}$

There are challenges to widespread adoption of CSII among people with T2DM (Table 1). Most people with T2DM are cared for by primary care healthcare providers who have minimal knowledge and exposure to CSII; most people with type 1 diabetes mellitus (T1DM) are cared by specialists in diabetes and endocrinology who have significant training and exposure to CSII. In addition, CSII technology may be complex and may be difficult for people with T2DM, who usually receive their diabetes diagnosis at a later stage in life than people with T1DM. People of an advanced age are less likely to adapt to new technology than younger people. The advanced age of people with T2DM introduces another potential barrier to CSII use in particular and insulin therapy in general: lifestyle interruptions. Most people with T1DM can begin to develop coping and management strategies at an early age. People with T2DM, however, must develop these management skills after most of their life habits are formed and must fit them around perhaps long-standing work and family obligations. Finally, initiation of CSII requires expenditures by the user or an insurance company. Medicare, for example, requires that its beneficiaries present substantial evidence of insulin deficiency before it will reimburse an insulin pump. The documentation requirements include the following: fasting C-peptide level $\leq 110 \%$ (or $\leq 200 \%$ if renal insufficiency) of the lower limit of normal of the laboratory's measurement method with a concurrently obtained fasting blood glucose $(\mathrm{BG}) \leq 225 \mathrm{mg} / \mathrm{dL}, 6$ months of MDI therapy, average four or more self-monitored BG tests per day for 2 months, and evidence of suboptimal glycemic control defined as an $\mathrm{HbA} 1 \mathrm{c} \geq 7.0 \%$, history of significant glycemic excursions, or history of severe hypoglycemia or hypoglycemic unawareness. ${ }^{4}$ These stringent requirements are in place because MDI therapy, even when it involves more than three injections per day, is less expensive than purchasing or renting an insulin pump and paying for ongoing pump supplies. Therefore, from a payor perspective, switching from MDI to CSII in people with T2DM must be more cost-effective than continuing MDI. Cost-effectiveness could be demonstrated in favor of CSII if the therapy provided an improvement in health outcomes that outweighs the increased cost of the insulin pump, related supplies, and training.

To overcome these barriers, CSII regimens and technologies for people with T2DM must effectively reduce glucose

Atlanta Diabetes Associates, Atlanta, Georgia. 
Table 1. Barriers to CSII Use by People with T2DM and Corresponding Research and Clinical Needs

Barriers to CSII use

Minimal knowledge and exposure to CSII

Complexity of CSII technology

Lifestyle interruptions

Insulin pump and supply expenditures
Research and clinical needs

Training by specialists

Simple insulin pumps

Age- and knowledge-specific CSII therapy regimens Cost-effectiveness studies levels, be simple and unobtrusive, and be cost-effective. This article reviews the available clinical evidence about CSII for the treatment of T2DM, including randomized controlled trials (RCTs) comparing CSII and MDI, studies of simple insulin dosing regimens, and feasibility trials of CSII-related therapies not yet in common use (Tables 2 and 3 ).

\section{RCTs of Studies Comparing CSII and MDI}

Studies comparing CSII and MDI in the treatment of T2DM have not yet yielded a definitive clinical picture. A recent meta-analysis of RCTs concluded that the available evidence indicates no difference between CSII and MDI in terms of mean $\mathrm{HbA} 1 \mathrm{c}$ reduction. ${ }^{16}$ The meta-analysis relied, however, on only four RCTs ${ }^{6-8,17}$ with heterogeneous study designs and target populations.

The first large RCT of CSII among people with T2DM was reported by Raskin et al. ${ }^{7}$ A total of 132 subjects were randomized to CSII with insulin aspart or MDI with insulin aspart and NPH insulin for 24 weeks. Subjects discontinued all oral antidiabetes drugs (OADs) and received recommended titration of insulin dosing for 8 weeks to a fasting BG of $80-120 \mathrm{mg} / \mathrm{dL}$, after which doses were maintained for the next 16 weeks unless necessity dictated otherwise. Subjects were CSII-naive, used insulin one or more times per day at baseline, and had mean baseline mean $\mathrm{HbA1c}$ values of $8.2 \%$ for CSII and $8.0 \%$ for MDI. CSII and MDI significantly reduced mean $\mathrm{HbA} 1 \mathrm{c}$ from baseline (to $7.6 \%$ for CSII and $7.5 \%$ for MDI), but there was no statistical difference between groups. Neither group reached the ADA-recommended $\mathrm{HbA} 1 \mathrm{c}$ value of $\leq 7.0 \%$. ${ }^{18}$ Although their $\mathrm{HbA} 1 \mathrm{c}$ reduction was no different from the MDI group, $93 \%$ of the CSII group preferred the study therapy to their previous insulin injection regimen for reasons of convenience, flexibility, ease of use, and overall preference. ${ }^{7}$ An analysis of treatment satisfaction surveys administered to subjects in this trial underscored their preference for CSII. Testa et al. ${ }^{15}$ reported that there was a statistically significant difference in favor of CSII for overall treatment satisfaction and all subscales.

A subsequent RCT of CSII among older adults with T2DM was reported by Herman et al. $^{6}$ A total of 107 people were randomized to CSII with insulin lispro or MDI with insulin lispro and insulin glargine for 1 year. Subjects received intensive titration of insulin dosing for 4 weeks, after which doses were maintained unless necessity dictated otherwise. Subjects were $\geq 60$ years of age, used insulin one or more times per day at baseline, and had mean baseline mean HbA1c of $8.4 \%$ for CSII and $8.1 \%$ for MDI. As in the study reported by Raskin et al., 7 both therapies significantly reduced mean $\mathrm{HbA} 1 \mathrm{c}$ from baseline (to $6.6 \%$ for CSII and $6.4 \%$ for MDI), and there was no statistical difference between groups. Unlike the previous RCT, however, both groups' mean $\mathrm{HbA} 1 \mathrm{c}$ at 12 months were below the ADA-recommended value of $7.0 \%$. Treatment satisfaction improved for both groups from baseline. The change in treatment satisfaction from baseline was statistically significant for both groups but not statistically significant between groups. ${ }^{6}$ The consensus from these two large trials is that CSII reduces $\mathrm{HbA} 1 \mathrm{c}$ and is preferred by users, but clinical superiority to MDI was not demonstrated in subjects for whom conventional insulin therapy has failed.

Although Raskin et al. ${ }^{7}$ and Herman et al. ${ }^{6}$ have reported the largest RCTs of CSII for T2DM to date, other smaller RCTs have been published that reported mean $\mathrm{HbA} 1 \mathrm{c}$ reductions in favor of CSII. Early work in this area began nearly 20 years ago, before recombinant insulin analogs became widely available. An early RCT comparing CSII with regular insulin and conventional insulin therapy with regular and NPH for T2DM was reported by Jennings et al. ${ }^{10}$ Reductions in median $\mathrm{HbA1c}$ favored CSII significantly after 4 months of treatment. ${ }^{10}$ More recently, a similarly small RCT used a crossover design and also arrived at an $\mathrm{HbA} 1 \mathrm{c}$ reduction favoring CSII over MDI. Berthe et al..$^{5}$ reported on 17 subjects who were

TABle 2. RCTs COMPARING CSII AND MDI FOR T2DM

\begin{tabular}{|c|c|c|c|c|c|c|c|}
\hline \multirow[b]{2}{*}{ Reference } & \multirow[b]{2}{*}{$\mathrm{n}^{\mathrm{a}}$} & \multirow[b]{2}{*}{ Design } & \multirow[b]{2}{*}{ Follow-up } & \multicolumn{3}{|c|}{$H b A 1 c(\%)(S D)$} & \multirow[b]{2}{*}{$\mathrm{P}$ value } \\
\hline & & & & Baseline & CSII & $M D I$ & \\
\hline Berthe et al. $^{5}$ & 17 & Crossover & 2 periods of 12 weeks & $9(1.6)$ & $7.7(0.8)$ & $8.6(1.6)$ & $<0.03$ \\
\hline Herman et al. ${ }^{6}$ & 107 & Parallel & 1 year & $\begin{array}{l}\text { CSII: } 8.4(1.1) \\
\text { MDI: } 8.1(1.2)\end{array}$ & $6.6(0.8)$ & $6.4(0.8)$ & 0.19 \\
\hline Raskin et al. ${ }^{7}$ & 132 & Parallel & 24 weeks & $\begin{array}{l}\text { CSII: } 8.2(1.4) \\
\text { MDI: } 8.0(1.1)\end{array}$ & $7.6(1.2)$ & $7.5(1.2)$ & NS \\
\hline Wainstein et al. ${ }^{8}$ & 40 & Crossover & 2 periods of 18 weeks & $\begin{array}{l}\text { CSII-MDI: } 10.1 \text { (1.6) } \\
\text { MDI-CSII: } 10.2(1.4)\end{array}$ & $-0.8(1.5)^{\mathrm{b}}$ & $+0.4(1.3)^{\mathrm{b}}$ & 0.007 \\
\hline
\end{tabular}

asubjects randomized.

${ }^{b} \mathrm{HbA} 1 \mathrm{c}$ values for CSII and MDI are presented by Wainstein et al. ${ }^{8}$ as direct treatment effect in the completers' cohort. 
Table 3. Other Studies of CSII for T2DM

\begin{tabular}{|c|c|c|c|c|c|c|}
\hline Reference & $\mathrm{n}^{\mathrm{a}}$ & Design & Therapy & Follow-up & Primary end point & Primary result \\
\hline Edelman et al. ${ }^{9}$ & 58 & Longitudinal & $\begin{array}{l}\text { CSII simple } \\
\text { dosing }\end{array}$ & 4 months & $\mathrm{HbA} 1 \mathrm{c}$ & $\begin{array}{l}\text { Significant } \\
\text { reduction } \\
\text { in } \mathrm{HbA} 1 \mathrm{c}\end{array}$ \\
\hline Jennings et al. ${ }^{10}$ & 20 & RCT & $\begin{array}{l}\text { CSII or } \\
\text { conventional } \\
\text { insulin }\end{array}$ & 4 months & $\mathrm{HbA} 1 \mathrm{c}$ & $\begin{array}{l}\text { Significant } \\
\text { reduction in } \\
\text { HbA1c } \\
\text { favoring CSII }\end{array}$ \\
\hline Kapitza et al. ${ }^{11}$ & 6 & Feasibility & $\begin{array}{l}\text { CSII with } \\
\text { simple } \\
\text { insulin pump }\end{array}$ & 7 days & $\begin{array}{l}\text { Glycemic } \\
\text { profiles }\end{array}$ & $\begin{array}{l}\text { Stable or } \\
\text { improved } \\
\text { glycemic } \\
\text { profiles }\end{array}$ \\
\hline $\begin{array}{l}\text { Labrousse- } \\
\text { Lhermine et al. }{ }^{12}\end{array}$ & 59 & Longitudinal & $\begin{array}{l}\text { CSII simple } \\
\text { dosing, two } \\
\text { regimens }\end{array}$ & 3 years & $\mathrm{HbA} 1 \mathrm{c}$ & $\begin{array}{l}\text { Significant } \\
\text { reduction in } \\
\text { HbA1c for } 2 \\
\text { CSII regimens }\end{array}$ \\
\hline Lane $^{13}$ & 9 & Feasibility & $\begin{array}{l}\text { CSII with } \\
\text { U-500 insulin }\end{array}$ & 3 months & $\mathrm{HbA} 1 \mathrm{c}$ & $\begin{array}{l}\text { Significant } \\
\text { reduction } \\
\text { in } \mathrm{HbA} 1 \mathrm{c}\end{array}$ \\
\hline Parkner et al. ${ }^{14}$ & 21 & Crossover & $\begin{array}{l}\text { Basal CSII } \\
\text { or insulin } \\
\text { glargine }\end{array}$ & $\begin{array}{l}2 \text { periods } \\
\text { of } 8 \text { days }\end{array}$ & $\begin{array}{l}\text { Insulin and } \\
\text { glycemic } \\
\text { profiles }\end{array}$ & $\begin{array}{l}\text { Improved } \\
\text { insulin and } \\
\text { glycemic } \\
\text { profiles } \\
\text { favoring CSII }\end{array}$ \\
\hline Testa et al. ${ }^{15}$ & 126 & RCT & CSII or MDI & 24 weeks & $\begin{array}{l}\text { Treatment } \\
\text { satisfaction }\end{array}$ & $\begin{array}{l}\text { Improved } \\
\text { treatment } \\
\text { satisfaction } \\
\text { favoring CSII }\end{array}$ \\
\hline
\end{tabular}

${ }^{a}$ Subjects randomized.

randomized to CSII with insulin lispro or MDI with insulin lispro and insulin glargine for 12 weeks and then crossed over to the other therapy (following a washout period). There were 5 days of hospitalization for the CSII group and 1-2 days for the MDI group. Mean $\mathrm{HbA} 1 \mathrm{c}$ decreased by $1.3 \%$ (to $7.7 \%$ ) for CSII but only $-0.4 \%$ (to $8.6 \%$ ) for MDI. ${ }^{5}$

The most substantial study to result in reduction in mean $\mathrm{HbA1c}$ favoring CSII over MDI for T2DM had a crossover design and was reported by Wainstein et al. ${ }^{8}$ The study randomized subjects to CSII with insulin lispro and MDI with regular insulin and NPH for 18 weeks each. Subjects were obese and used high doses of insulin $(>1 \mathrm{U} / \mathrm{kg} /$ day). The mean $\mathrm{HbA} 1 \mathrm{c}$ end of treatment effect among subjects who completed the study was $-0.8 \%$ for CSII and $0.4 \%$ for MDI, a statistically significant difference between groups. Subjects initially treated with CSII (designated Group 2) experienced a $0.5 \%$ lower $\mathrm{HbA} 1 \mathrm{c}$ than subjects initially treated with MDI (designated Group 1): 8.4\% for Group 1, 7.9\% for Group 2. After these groups crossed over to the other treatment, the mean $\mathrm{HbA1c}$ for both was $8.8 \%$, indicating that the improvement that Group 2 initially experienced was interrupted by switching to MDI. ${ }^{8}$ These positive results indicate that CSII may be clinically effective in T2DM when using the correct treatment regimen.

\section{Simple Insulin Dosing Regimen with CSII in T2DM}

One possibility for optimizing CSII for the treatment of T2DM is simplifying the insulin dosing regimen. Indeed, people with T2DM who still have some residual beta-cell function may not require the complex regimens used by many CSII users with T1DM. Therefore, recent studies have investigated whether CSII for T2DM has long-term benefits and can improve glycemic control using a simple dosing regimen.

Labrousse-Lhermine et al. ${ }^{12}$ reported the first longitudinal long-term study of CSII for T2DM. Fifty-nine subjects were randomized to two simple dosing regimens. Group A had a fixed basal rate $<0.25 \mathrm{U} / \mathrm{kg} /$ day, and its preprandial boluses were adjusted to achieve postprandial BG levels of $<180 \mathrm{mg} / \mathrm{dL}$. Group B had no boluses and had a fixed daytime basal rate $<0.25 \mathrm{U} / \mathrm{kg} /$ day, and its nighttime basal rate was adjusted by $0.2 \mathrm{U} / \mathrm{h}$ in order to attain a fasting BG level of $<120 \mathrm{mg} / \mathrm{dL}$. Both groups used OADs. Subjects received minimal training on insulin pump operation, and basal rate settings were adjusted if necessary in consultation with the physician. Boluses for Group A were not altered after titration, and boluses were not added to Group B's treatment regimen. $\mathrm{HbA} 1 \mathrm{c}$ decreased similarly for both groups for years 1,2 , and 3 . The reduction in $\mathrm{HbA} 1 \mathrm{c}$ was significant from baseline $(9.5 \%)$ to years 1,2 , and $3(7.8 \%, 8.1 \%$, and $8.3 \%$, respectively). Secondary measures (minor and severe hypoglycemia, weight gain, quality of life) were also similar between groups. ${ }^{12}$

Two other studies provide evidence for simple dosing regimens in the very short term and after 4 months. Parkner et al. ${ }^{14}$ reported a study in which 21 subjects were randomized to receive equivalent doses of insulin via CSII or a once-daily injection of insulin glargine followed by a crossover to the other therapy. The dose level for each treatment period was dictated by the subject's baseline insulin glargine use. 
Although no dosage adjustments for glycemic variability were made and the doses were equivalent, CSII use was associated with lower area under the curve, a smoother glycemic curve, and lower variability in exogenous fasting insulin levels. Edelman et al. ${ }^{9}$ reported a 4-month longitudinal pilot study. Sixty subjects divided into three equal cohorts (two or more OADs only, basal insulin \pm OADs only, or $\mathrm{MDI} \pm$ OADs) with $\mathrm{HbA1}$ c $7-10.5 \%$ were switched from their baseline treatment to CSII using insulin glulisine. Initial recommended starting dose on the pump was 0.5 times the patient's weight, with half being given as a single basal rate and the remainder divided into three meal boluses. Dosing was adjusted weekly for 4 weeks by the investigators based on downloaded blinded continuous glucose monitoring (CGM) tracings with the goal to keep all glucose values within the prespecified target glucose of $70-130 \mathrm{mg} / \mathrm{dL}$ (preprandial) and $<180 \mathrm{mg} / \mathrm{dL}$ (postprandial). Mean $\mathrm{HbA} 1 \mathrm{c}$ reduced significantly in all three cohorts after 4 months of CSII from $8.4 \%$ to $7.2 \%$; among subjects with $\mathrm{HbA} 1 \mathrm{c}>8.5 \%$, the mean $\mathrm{HbA} 1 \mathrm{c}$ was reduced by $2.1 \%$. Although subjects could adjust their insulin dosing, $88 \%$ used two or fewer basal rates at the end of the study $(70 \%$ used one rate, $18 \%$ used two rates, and $12 \%$ used two or more basal rates). The mean daily basal, bolus, and total insulin doses at the end of the study were $49 \pm 30 \mathrm{U}$, $45 \pm 35 \mathrm{U}$, and $94 \pm 61 \mathrm{U}(0.94 \mathrm{U} / \mathrm{kg})$. All three cohorts preferred their new therapy with the pump compared to their prior therapy. These studies, taken together, provide compelling evidence that simple insulin dosing with T2DM leads to improved clinical outcomes.

\section{Future Directions?}

CSII was designed for use in T1DM; therefore, insulin pumps on the market have complex features for basal-bolus regimens and are indicated for use with U-100 insulin. It has been speculated that people with T2DM may not require the complexity (and ensuing cost) of currently available insulin pumps and that they may benefit from lower volumes of concentrated insulin formulations such as U-500 insulin. In addition, simple disposable patch pumps with only one basal rate and simple meal dosing are in development.

Kapitza et al. ${ }^{11}$ reported a proof-of-concept study of a oncedaily disposable insulin pump. Subjects in the study used the insulin pump for 3 days in the inpatient setting and 4 days in the outpatient setting; BG levels and CGM were used to assess glycemic outcomes. Fasting BG levels were similar at baseline and throughout the study. Most other BG readings were similar to baseline, and subjects' overall glycemic variability as measured by CGM decreased nonsignificantly (i.e., mean value was $173 \mathrm{mg} / \mathrm{dL}$ at baseline and $157 \mathrm{mg} / \mathrm{dL}$ during $\mathrm{V}-\mathrm{Go}^{\mathrm{TM}}$ [Valeritas Inc., Bridgewater, NJ] use). ${ }^{11}$

U-500 insulin has been investigated by Lane, ${ }^{13}$ who reported a retrospective study of nine subjects who used this insulin with CSII for 3 months. Subjects' mean HbA1c was reduced significantly by $1.1 \%$, and all subjects indicated a preference for U-500 over their previous insulin regimens. ${ }^{13}$ Lane et al. ${ }^{19}$ later reviewed the clinical evidence about the use of U-500 insulin for T2DM, regardless of whether CSII was the method of administration. Of eight studies reviewed, seven were retrospective, six only included subjects with T2DM, three included subjects with both T1DM and T2DM, and three only used CSII for insulin delivery. Of the studies using U-500 with CSII for T2DM, the study populations were four, six, and nine subjects with a duration of 3 months or 6 months. All of these latter studies resulted in reductions in mean $\mathrm{HbA} 1 \mathrm{c}$, two of which were statistically significant (one of the studies was a case series that did not perform a statistical analysis of mean $\mathrm{HbA1c}) .{ }^{13,20,21}$ With such low study populations, the overall efficacy of U-500 administered by CSII for T2DM cannot yet be verified. ${ }^{19}$

\section{Conclusions}

The available clinical evidence on CSII for T2DM is not yet consistent. RCTs have consistently shown that CSII reduces glucose, as demonstrated by HbA1c. When compared to MDI, CSII has resulted in both equivalent and lower $\mathrm{HbA1c}$ values. There are not many studies available for evaluation, and they are heterogeneous in design and subject population. However, some RCTs and other studies have shown clinical benefits of CSII for T2DM, particularly with simple insulin dosing regimens. Moreover, study subjects have indicated a preference for CSII, leading researchers to speculate how insulin pump use can be expanded among people with T2DM. The use of simpler insulin pumps and concentrated insulin formulations (e.g., U-500) are products of this speculation but are still largely untested options for people with T2DM.

A number of research needs remain to better understand how best to implement CSII for T2DM on a broader scale. One gap in our understanding is whether CSII provides incremental clinical benefits after MDI has failed in treating T2DM. Therefore, researchers should consider conducting RCTs comparing CSII and MDI after the latter therapy has failed. Along with this clinical effectiveness research, we need more data on selecting which people with T2DM should receive insulin pumps. We need more data on whether insulin pumps are cost-effective, especially in comparison to continuing MDI after it has failed to obtain glycemic goals. Further development of simple insulin pumps dedicated to treating T2DM would be helpful in bringing CSII to a broader base of users. All of these therapies would contribute to the ultimate goal of all diabetes management, regardless of type: providing a closed loop or artificial pancreas.

Despite these research gaps, the presently available evidence demonstrates that CSII improves glucose control, even with a simple insulin regimen. CSII also improves measures of quality of life and treatment satisfaction. As such, CSII may be a suitable option for people with T2DM who have not reached their glycemic goals.

\section{Acknowledgments}

Tim Peoples, M.A., an employee of Medtronic, Inc., provided writing assistance for this article.

\section{Author Disclosure Statement}

B.W.B. has received research support from the Juvenile Diabetes Research Foundation, Johnson \& Johnson Inc., Medtronic Inc., Novo Nordisk A/S, and Valeritas Inc. He has also served on the speaker's bureaus of Eli Lilly \& Co., Medtronic Inc., Novo Nordisk A/S, and sanofi-aventis; on advisory panels for Johnson \& Johnson Inc., Medtronic Inc., Novo Nordisk A/S, and Valeritas Inc.; and as a consultant to Johnson \& Johnson Inc., Medtronic Inc., and Novo Nordisk A/S. 


\section{References}

1. Nathan DM, Buse JB, Davidson MB, Ferrannini E, Holman RR, Sherwin R, Zinman B; American Diabetes Association; European Association for Study of Diabetes: Medical management of hyperglycemia in type 2 diabetes: a consensus algorithm for the initiation and adjustment of therapy: a consensus statement of the American Diabetes Association and the European Association for the Study of Diabetes. Diabetes Care 2009;32:193-203.

2. Holman RR, Farmer AJ, Davies MJ, Levy JC, Darbyshire JL, Keenan JF, Paul SK; the 4-T Study Group: Three-year efficacy of complex insulin regimens in type 2 diabetes. N Engl J Med 2009;361:1736-1747.

3. Polonsky KS, Given BD, Hirsch LJ, Tillil H, Shapiro ET, Beebe C, Frank BH, Galloway JA, Van Cauter E: Abnormal patterns of insulin secretion in non-insulin-dependent diabetes mellitus. N Engl J Med 1988;318:1231-1239.

4. Centers for Medicare \& Medicaid Services: Infusion Pumps: C-Peptide Levels as a Criterion for Use. Medicare National Coverage Determinations. Publication 100-03. Change Request 3705. Effective December 17, 2004. Implemented February 18, 2005. http://www.cms.hhs.gov/transmittals/ downloads/R27NCD.pdf. (accessed December 18, 2009).

5. Berthe E, Lireux B, Coffin C, Goulet-Salmon B, Houlbert D, Boutreux S, Fradin S, Reznik Y: Effectiveness of intensive insulin therapy by multiple daily injections and continuous subcutaneous infusion: a comparison study in type 2 diabetes with conventional insulin regimen failure. Horm Metab Res 2007;39:224-229.

6. Herman WH, Ilag LL, Johnson SL, Martin CL, Sinding J, Al Harthi A, Plunkett CD, LaPorte FB, Burke R, Brown MB, Halter JB, Raskin P: A clinical trial of continuous subcutaneous insulin infusion versus multiple daily injections in older adults with type 2 diabetes. Diabetes Care 2005;28: 1568-1573.

7. Raskin P, Bode BW, Marks JB, Hirsch IB, Weinstein RL, McGill JB, Peterson GE, Mudaliar SR, Reinhardt RR: Continuous subcutaneous insulin infusion and multiple daily injection therapy are equally effective in type 2 diabetes: a randomized, parallel-group, 24-week study. Diabetes Care 2003;26:2598-2603.

8. Wainstein J, Metzger M, Boaz M, Minuchin O, Cohen Y, Yaffe A, Yerushalmy Y, Raz I, Harman-Boehm I: Insulin pump therapy vs. multiple daily injections in obese type 2 diabetic patients. Diabet Med 2005;22:1037-1046.

9. Edelman SV, Bode BW, Bailey TS, Kipnes MS, Frias JP: Continuous subcutaneous insulin infusion in patients with type 2 diabetes safely improved glycemic control using a simple insulin dosing regimen [abstract]. Diabetes 2009; 58 (Suppl 1):A113.

10. Jennings AM, Lewis KS, Murdoch S, Talbot JF, Bradley C, Ward JD: Randomized trial comparing continuous subcutaneous insulin infusion and conventional insulin therapy in type II diabetic patients poorly controlled with sulfonylureas. Diabetes Care 1991;14:738-744.

11. Kapitza C, Fein S, Heinemann L, Schleusener D, Levesque S, Strange P: Basal-prandial insulin delivery in type 2 diabetes mellitus via the V-Go: a novel continuous subcutaneous infusion device. J Diabetes Sci Technol 2008;2:40-46.

12. Labrousse-Lhermine F, Cazals L, Ruidavets JB, Hanaire H: Long-term treatment combining continuous subcutaneous insulin infusion with oral hypoglycaemic agents is effective in type 2 diabetes. Diabetes Metab 2007;33:253-260.

13. Lane WS: Use of U-500 regular insulin by continuous subcutaneous insulin infusion in patients with type 2 diabetes and severe insulin resistance. Endocr Pract 2006;12:251-256.

14. Parkner T, Laursen T, Vestergaard ET, Hartvig H, Smedegaard JS, Lauritzen T, Christiansen JS: Insulin and glucose profiles during continuous subcutaneous insulin infusion compared with injection of a long-acting insulin in type 2 diabetes. Diabet Med 2008;25:585-591.

15. Testa MA, Hayes JF, Turner RR, Simonson DC: Patient acceptance and satisfaction with intensive insulin therapy in type 2 diabetes: a randomized trial of the insulin pen vs. pump [abstract]. Diabetes 2001;50 (Suppl 2):A428.

16. Monami M, Lamanna C, Marchionni N, Mannucci E: Continuous subcutaneous insulin infusion versus multiple daily insulin injections in type 2 diabetes: a meta-analysis. Exp Clin Endocrinol Diabetes 2009;117:220-222.

17. Weng J, Li Y, Xu W, Shi L, Zhang Q, Zhu D, Hu Y, Zhou Z, Yan X, Tian H, Ran X, Luo Z, Xian J, Yan L, Li F, Zeng L, Chen Y, Yang L, Yan S, Liu J, Li M, Fu Z, Cheng H: Effect of intensive insulin therapy on beta-cell function and glycaemic control in patients with newly diagnosed type 2 diabetes: a multicentre randomized parallel-group trial. Lancet 2008; 371:1753-1760.

18. American Diabetes Association: Standards of medical care in diabetes-2009. Diabetes Care 2009;32(Suppl 1):S13-S61.

19. Lane WS, Cochran EK, Jackson JA, Scism-Bacon JL, Corey IB, Hirsch IB, Skyler JS: High-dose insulin therapy: is it time for U-500 insulin? Endocr Pract 2009;15:71-79.

20. Bulchandani DG, Konrady T, Hamburg MS: Clinical efficacy and patient satisfaction with U-500 insulin pump therapy in patients with type 2 diabetes. Endocr Pract 2007;13:721-725.

21. Knee TS, Seidensticker DF, Walton JL, Solberg LM, Lasseter DH: A novel use of U-500 insulin for continuous subcutaneous insulin infusion in patients with insulin resistance: a case series. Endocr Pract 2003;9:181-186.

Address correspondence to: Bruce W. Bode, M.D., F.A.C.E. Atlanta Diabetes Associates 77 Collier Road, Suite 2080 Atlanta, GA 30309

E-mail: bbode001@aol.com 
